\title{
Eighteen trial-level parity judgment datasets $(n=1016)$ from five countries: benefits of sharing unified data of cognitive tasks
}

\author{
Krzysztof Cipora $^{1 *}$, Jean-Philippe van Dijck ${ }^{2,3}$, Carrie Georges ${ }^{4}$, Nicolas Masson ${ }^{4,5}$, Silke M. \\ Göbel $^{6,7}$, Klaus Willmes ${ }^{8}$, Mauro Pesenti ${ }^{5}$, Christine Schiltz ${ }^{4}$, \& Hans-Christoph Nuerk ${ }^{9,10}$ \\ ${ }^{1}$ Centre for Mathematical Cognition, Loughborough University, Loughborough, UK \\ 2 Department of Experimental Psychology, Ghent University, Belgium \\ ${ }^{3}$ Department of Applied Psychology: Thomas More University of Applied Sciences, Belgium \\ ${ }^{4}$ Institute of Cognitive Science and Assessment, Department of Behavioral and Cognitive \\ Science, University of Luxembourg, Luxembourg \\ ${ }^{5}$ Institut de Recherche en Sciences Psychologiques and Institute of Neuroscience, \\ Université catholique de Louvain, Louvain-la-Neuve, Belgium \\ ${ }^{6}$ Department of Psychology, University of York, York, UK \\ 7 Department of Special Needs Education, University of Oslo, Norway \\ ${ }^{8}$ Department of Neurology, University Clinic, RWTH Aachen University, Aachen Germany \\ ${ }^{9}$ Department of Psychology, University of Tuebingen, Tuebingen, Germany \\ ${ }^{10}$ LEAD Graduate School \& Research Network, University of Tuebingen, Tuebingen, \\ Germany
}

Running title: One task, many datasets

* Corresponding author: Centre for Mathematical Cognition, Wavy Top Building.

Loughborough University, LE11 3TU United Kingdom. E-mail: k.cipora@lboro.ac.uk 


\section{Abstract}

Psychological science could greatly benefit from research synthesis, especially when it comes to overcoming limitations of too small samples tested in single studies. However, initiatives aimed at sharing large, curated trial-level data from cognitive tasks remain scarce. To address this problem, we initiated a collective effort allowing to assemble and report a collection of eighteen datasets of the speeded bimanual parity judgment of single-digit numbers with response-to-key assignment flipped midexperiment (hereafter SNARC-B-PJ). SNARC-B-PJ is one of the most popular tasks in numerical cognition and is used to evaluate the Spatial-Numerical Association of Response Codes effect (SNARC), a hallmark effect for Spatial-Numerical Associations (SNAs) more generally. Datasets, related to both published and unpublished studies, were collected in eight labs across five countries, totaling 1016 healthy adult participants. We provide thorough documentation and a tentative outline of potential future analyses of these datasets. We also intend to expand this resource and encourage potentially interested colleagues to contribute to this database. At the same time, we generalize our approach by discussing potential benefits of building similar databases comprising data from other popular tasks used in cognitive psychology.

185 words

Keywords: dataset, research synthesis, parity judgment, SNARC 


\section{Introduction}

\section{On the need of data syntheses}

The evidential value of a single study is usually limited. Therefore, nowadays in the face of the replication crisis in psychology, it is becoming increasingly important to combine evidence from multiple studies (Open Science Collaboration, 2015). The traditional way of doing that is meta-analysis. Before data sharing became popular, one had to extract effect sizes from existing published (and even more importantly unpublished) studies and unify them, which in several cases was a non-trivial task. However, when having available effect sizes only, the analytic toolbox one had was restricted in important aspects, because only aggregated, sample-level statistics (Means, SD, effect sizes) could be used for reanalyses. To give a prominent example: For the investigation of gender effects, one cannot directly compare men and women with each other, but can examine such effects only indirectly, by using the proportion of males and females as a moderator variable across different studies. Because studies can differ in many aspects besides gender distribution, some of which may not be reported fully for a subsequent meta-analysis or even be unknown to researchers, the proportions of gender in the sample remains a very noisy measure. This is just one example of a much more general problem, when only sample-level characteristics can be compared.

To address such problems, relatively recently another approach was proposed, called Integrative Data Analysis (IDA; Curran \& Hussong, 2009; Hussong et al., 2013). This approach gained popularity mostly in clinical and personality psychology. IDA is meant to be an extension of a meta-analysis, in which the analysis is not conducted on effect sizes but goes down to the participant level (e.g., gender of the individual). Sometimes, it requires accounting for differences in specific measures being used. Studies can be included as either random or fixed effects (Hussong et al., 2013). However, IDA has not gained much interest in cognitive psychology yet.

When considering IDA-like approaches to be used in cognitive psychology experiments, some more specificities should be accounted for, therefore we postulate that the analysis needs to go even deeper - to the single trial level. Despite investigating the same phenomenon (e.g., Stroop interference, flanker effects), experiments differ both at the level of the experimental procedure used and data processing, and effects of these two seem to be strongly interleaved (e.g., one lab 
routinely uses specific task parameters and analysis pipeline, while another lab uses different configuration of these parameters). Differences in experimental procedure such as different numbers of experimental blocks and trials within these blocks, trial timings, response devices and so on cannot be resolved fully using data synthesis. At the same time, experiments differ as regards data evaluation such as: data cleaning, aggregation, statistical models used. These differences can be addressed during the trial-level data synthesis - one can apply unified data processing pipeline(s) across all datasets to equalize its effect on observed results across datasets. Unified data treatment procedure not only allows equalizing its effect across datasets, but also can help understanding effects of differences in experimental procedures as one can isolate their influence from the effects of data treatment. For this reason, we believe that collecting large databases of trial-level data for cognitive psychology can help advance the field. In this work, we specifically focus on reaction time data for one of the most frequently used tasks in numerical cognition to measure Spatial-Numerical Associations. Such an approach can be used in case of any popular cognitive measure.

\section{Spatial-Numerical Associations}

Numerous studies using different paradigms and setups and testing different groups have demonstrated that there is a clear association between numbers and directions in space (Cipora et al., 2018, 2020; Toomarian \& Hubbard, 2018). One of the most spectacular hallmarks of these Spatial-Numerical Associations (SNAs) is the Spatial-Numerical Association of Response Codes (SNARC) effect (Cipora, Soltanlou, et al., 2019; Dehaene et al., 1993; Wood et al., 2008). This term denotes a phenomenon that, in speeded binary response settings, responses to relatively small/large magnitude numbers are faster on the left/right side respectively. The SNARC effect is one of the most thoroughly investigated phenomena in numerical cognition. Typically, it is measured with speeded bimanual parity judgment of singledigit numbers with response-to-key assignment flipped mid-experiment (for other measures see Wood et al., 2008). In this paper we focus on this specific type of the parity judgment task, using the term SNARC-B-PJ to emphasize that this is not only bimanual parity judgment tasks being used (e.g., Cipora et al., 2021; Heubner et al., 2018). 
SNARC-B-PJ

The SNARC-B-PJ allows investigating whether and how numerical magnitudes are automatically processed. Specifically, judging whether a number is odd or even does not require participants to consider the magnitude of the number. However, as we discussed above, even in such a setup numerical magnitude influences response patterns - reaction times and accuracies. For this reason, the SNARC-B-PJ has become very popular, and its different variations have been used in many labs.

At a first glance the specific task characteristics of the SNARC-B-PJ seem clearly defined, however, the implementations of the task differ substantially between labs and studies (see Table 2 for an overview of parameters differing for our studies alone). Even though they have not all been systematically investigated, there are some hints that these parameters play a role for the SNARC effect and potentially also other phenomena that can be tackled with the SNARC-B-PJ. For instance, some methodological studies show that specific task parameters such as the number of repetitions of each number (Cipora \& Wood, 2017) or the duration of the intertrial interval (Brigadoi et al., 2018) influence the SNARC effect and its reliability. The specific order of trials can also affect the SNARC effect (Gökaydin et al., 2018; Pfister et al., 2013). Although there is currently less evidence for other parameters, one can expect that they also do play a role. For instance, the time the eye fixation point is presented before the number is presented can affect reaction times in SNARC-B-PJ as it does in other cognitive tasks (e.g., Vallesi et al., 2006), and thus affect the SNARC effect (Cipora \& Nuerk, 2013; Gevers et al., 2006). At the same time, some parameters such as distance between response keys do not seem to play a role (Schiller et al., 2016).

To sum up, there are multiple differences between different implementations of the SNARC-B-PJ. There is evidence that at least some of them influence the SNARC effect and potentially other effects measured with the task.

\section{The present database}

Here we present 18 unified SNARC-B-PJ raw datasets collected in eight different labs in five countries (see Table 1 for an overview). They were prepared as a part of a multi-lab initiative aimed at investigating the prevalence of the SNARC effect (Cipora, van Dijck, et al., 2019). Here we present an exhaustive description of these 
openly available datasets and provide basic data quality checks. We propose potential future reanalyses, which can be pursued using this database, and discuss potential benefits of similar endeavors in other areas of cognitive psychology.

\section{Method}

\section{Included datasets}

Overall, the database comprises data from 1016 participants ( 635 females and 361 males; for 20 participants, gender data was not available), whose age ranged from 17 to 81 years old. Their background and demographic characteristics are presented in Table 1. We considered only datasets in which non-clinical adult samples were tested. Importantly, some of them comprise non-university students.

\section{Task parameters}

All participants were tested using a SNARC-B-PJ. In most of the cases, each trial comprised a fixation point (duration between 300 and $1500 \mathrm{~ms}$ ), the subsequent presentation of an Arabic numeral with different response deadline, and an intertrial interval (Table 2). Studies differed considerably as regards the number of repetitions of each numeral in each hand-to-parity block, ranging from 9 to 32 . When these data have been collected, there were no systematic methodological studies on the effect of these parameters. Therefore, different labs have adopted different parameters and have been using them. Various experimental software packages were used to collect the data (DMDX, Forster \& Forster, 2003; E-Prime, Psychology Software Tools, Pittsburgh, PA; Super Lab, Cedrus, Phoenix, Arizona; Presentation, Neurobehavioral Systems, Inc., Berkeley, CA). Studies used different response devices: standard computer keyboard (using different keys) or response keys (Table 2). In most cases (14 studies), the order of blocks was counterbalanced, and in 4 of them it was fixed starting with right-even left-odd assignment. In all studies except one (Nuerk et al., 2005), two blocks were administered directly one after another.

The order of trials was randomized for each participant by the program controlling the experiment. In five datasets, no restriction was put on the randomization produced. In six datasets, all numbers in the set were presented in a randomized order, and such a routine was repeated a given number of times. In four datasets restrictions were put on the possible number of repetitions of the same number and 
on the number of consecutive responses with the same button. Three datasets comprised randomization in subsets of 64 trials and no consecutive presentation of the same number was allowed (Table 2).

Thirteen datasets comprised numbers 1-4 and 6-9, which is the most typical setup for a parity judgment task; five datasets comprised all single-digit numbers between 0 and 9 . 
Table 1 Sample descriptions of considered datasets

\begin{tabular}{|c|c|c|c|c|c|c|}
\hline Data set & $\mathrm{n}$ & $\begin{array}{l}\text { Age } \\
\text { (SD) }\end{array}$ & $\begin{array}{c}\text { Gender } \\
(\mathrm{f} / \mathrm{m})\end{array}$ & Mother tongue & Background & Comments \\
\hline $\begin{array}{l}\text { Cipora et al. } \\
(2009)\end{array}$ & 43 & $\begin{array}{l}22.0 \\
(1.8)\end{array}$ & $33 / 10$ & Polish & Students from Jagiellonian University, Cracow & no restrictions \\
\hline $\begin{array}{l}\text { Cipora \& Göbel } \\
(2013)\end{array}$ & 51 & $\begin{array}{l}23.2 \\
(4.9)\end{array}$ & $30 / 21$ & English & Students from the University of York & no restrictions \\
\hline $\begin{array}{l}\text { Cipora \& Nuerk } \\
(2013)\end{array}$ & 71 & $\begin{array}{l}21.8 \\
(1.9) \\
\end{array}$ & $49 / 22$ & Polish & Humanities and math-related subjects students & no restrictions \\
\hline $\begin{array}{l}\text { Cipora et al. } \\
\text { (2016) }\end{array}$ & 44 & $\begin{array}{l}27.9 \\
(1.1)\end{array}$ & $6 / 38$ & Polish & $\begin{array}{l}\text { Advanced doctoral students: math, engineering, } \\
\text { humanities and social sciences }\end{array}$ & no physics students \\
\hline Cipora (2014) & 55 & $\begin{array}{l}23.1 \\
(3.7)\end{array}$ & $39 / 16$ & Polish & General population & $\begin{array}{l}\text { no psychology } \\
\text { students }\end{array}$ \\
\hline $\begin{array}{l}\text { Georges et al. } \\
(2016)\end{array}$ & 61 & $\begin{array}{l}23.3 \\
(3.2)\end{array}$ & $27 / 34$ & heterogeneous & Students from University of Luxembourg & $\begin{array}{l}\text { no psychology } \\
\text { students }\end{array}$ \\
\hline $\begin{array}{l}\text { Georges et al. } \\
(2017)\end{array}$ & 81 & $\begin{array}{l}23.4 \\
(3.2) \\
\end{array}$ & $40 / 41$ & heterogeneous & Students from University of Luxembourg & $\begin{array}{l}\text { no psychology } \\
\text { students }\end{array}$ \\
\hline $\begin{array}{l}\text { Georges et al. } \\
(2018)\end{array}$ & 26 & $\begin{array}{l}26.9 \\
(3.3) \\
\end{array}$ & $15 / 11$ & heterogeneous & $\begin{array}{l}\text { Students from University of Luxembourg; } \\
\text { meeting diagnostic criteria of ADHD }\end{array}$ & $\begin{array}{l}\text { no psychology } \\
\text { students }\end{array}$ \\
\hline $\begin{array}{l}\text { Georges et al. } \\
\text { (unpubl.) }\end{array}$ & 55 & $\begin{array}{l}24.8 \\
(3.4)\end{array}$ & $35 / 20$ & heterogeneous & Students from University of Luxembourg & no restrictions \\
\hline $\begin{array}{l}\text { Ginsburg et al. } \\
\text { (unpubl.) }\end{array}$ & 192 & $\begin{array}{l}19.4 \\
(3.7)\end{array}$ & $161 / 31$ & French & Students from Université Libre de Bruxelles & no restrictions \\
\hline Göbel (unpubl.) & 38 & $\begin{array}{l}23.4 \\
(4.8)\end{array}$ & $25 / 13$ & English & Students from the University of York & no restrictions \\
\hline $\begin{array}{l}\text { Göbel et al. } \\
(2015)\end{array}$ & 55 & $\begin{array}{l}20.1 \\
(2.3) \\
\end{array}$ & $45 / 10$ & English & Students from the University of York & no restrictions \\
\hline $\begin{array}{l}\text { Masson \& } \\
\text { Pesenti (unpubl.) }\end{array}$ & 28 & $\begin{array}{l}21.7 \\
(1.8)\end{array}$ & $17 / 11$ & French & Students from Université catholique de Louvain & no restrictions \\
\hline $\begin{array}{l}\text { Nuerk et al. } \\
(2005)\end{array}$ & 32 & $\begin{array}{l}26.2 \\
(4.9) \\
\end{array}$ & $16 / 16$ & German & $\begin{array}{l}\text { Students and research staff of the University } \\
\text { Hospital Aachen }\end{array}$ & no restrictions \\
\hline $\begin{array}{l}\text { van Dijck et al. } \\
(2009)\end{array}$ & 40 & $\begin{array}{l}19.2 \\
(1.7)^{\mathrm{a}}\end{array}$ & $15 / 5 / 20 ?^{a}$ & Dutch & Students from Ghent University & no restrictions \\
\hline
\end{tabular}




\begin{tabular}{|c|c|c|c|c|c|c|}
\hline $\begin{array}{l}\text { van Dijck et al. } \\
\text { (unpubl., a) }\end{array}$ & 63 & $\begin{array}{l}19.7 \\
(1.9)\end{array}$ & $39 / 24$ & Dutch & $\begin{array}{l}\text { Students from Thomas More University College } \\
\text { Antwerp }\end{array}$ & no restrictions \\
\hline $\begin{array}{l}\text { van Dijck et al. } \\
\text { (unpubl., b) }\end{array}$ & 41 & $\begin{array}{l}19.9 \\
(2.1)^{b}\end{array}$ & $23 / 18$ & Dutch & $\begin{array}{l}\text { Students from Thomas More University College } \\
\text { Antwerp }\end{array}$ & only smokers \\
\hline $\begin{array}{l}\text { van Dijck et al. } \\
\text { (unpubl., c) }\end{array}$ & 40 & $\begin{array}{l}34.3 \\
(18.3)\end{array}$ & $20 / 20$ & Dutch & General population & no restrictions \\
\hline
\end{tabular}

a demographic data of 20 participants was not available any more

b age data from 2 participants were missing 
Shared datasets

All datasets are deposited on Open Science Framework at https://osf.io/y2ajg/ and follow a unified structure, which allows running the same analysis script on all datasets. The datasets are stored in the following folders:

\section{"Raw_data_sets_as_reported_in_the_paper"}

This folder contains data files considered in the main analyses in Cipora, van Dijck, et al. (2019). Specifically, from datasets where the taskset also contained numbers 0 and 5 , these numbers were excluded before any other operation was conducted on the data. Full datasets considering these numbers can be found in the folder “Datasets_with_0_and_5” (see below).

The data are stored in long format (i.e., one row corresponds to one trial). Each file corresponds to one dataset. In all datasets, data from practice blocks are excluded. In each dataset, the order of rows follows the order of trials presented to a given participant.

Each file comprises the following variables:

part.code - unique identifier of a participant - contains name of the dataset and participant number used in each experiment. Participant numbers are completely arbitrary and are used solely to differentiate one participant from another. The code is repeated in all rows corresponding to trials performed by a given participant. Participant codes correspond to those in the "Block_order_demographics" folder (see below).

age - participant's age in years (integers only). Not available for Masson \& Pesenti (unpubl.) and for some participants in van Dijck et al. (2009). This information is replicated across all rows corresponding to a given participant.

gender - participant's gender: values $F, M$ and $N A$. This information is replicated across all rows corresponding to a given participant.

block.order - order of blocks (i.e., response to hand assignment) administered to a given participant. Two values are possible for this variable: start_even_right and start_even_left. This information is replicated across all rows corresponding to a given participant.

block.no - block number according to order of administration: Possible values: 1 = first block in the experiment, 2 = second block in the experiment (in Nuerk et al., 2005 this refers only to blocks comprising Arabic numbers). 
series - Present in 6 datasets: Cipora \& Nuerk, 2013; Cipora \& Goebel, 2013; Cipora, 2014; Cipora et al., 2016; Goebel et al., 2015, Goebel, unpubl. In these datasets randomization of trials was done in such a way that all possible numerals were presented in random order, and only when all had been presented, the same set was presented again in some randomized order. Therefore, one could differentiate series in which all numerals appeared. For each block in each participant numbered continuously from 1 to the number corresponding to number of repetitions of each numeral per block.

trial.no - trial number. Continuous numbering from 1 until the number of the last trial performed by a given participant. Note that in case of 5 datasets, in which 0 and 5 were excluded post hoc, trial numbering was added after exclusion (see "Datasets_with_0_and_5" below).

number - numeral presented to the participant in a given trial. Possible values: $1,2,3,4,6,7,8,9$.

resp.side - response side, on which the correct response button was located. Please note that this indicates location of the correct response, not the actual key that was pressed (this is different in case of an incorrect response). Possible values: left and right.

$r t$ - reaction time in milliseconds.

correct.experimental - filtering variable excluding incorrect responses and trials in which participants did not respond at all. Possible values: $0=$ incorrect response / no response, 1 = correct response.

The last two variables are specific to the analysis approach taken by Cipora, van Dijck et al. (2019), and can be ignored if one decides on another way of data trimming or filtering:

filter.correct.exp.antic - filtering variable excluding anticipations $<200$ milliseconds. Its value also equals zero for incorrect responses (indicated by correct.experimental above). Possible values: $0=$ invalid trial, $1=$ valid trial.

filter.seq - sequential filter (Cipora \& Nuerk, 2013) as described in the main analysis in Cipora, van Dijck et al. (2019). Outlier reaction times (deviating by more than 3 SD from the individual mean for each participant) were sequentially trimmed. 
Its value also equals zero for incorrect responses and anticipations (indicated by filter.correct.exp.antic above). Possible values: $0=$ invalid trial, $1=$ valid trial.

\section{"Datasets_with_0_and_5"}

In 5 datasets (Cipora et al., 2009; Cipora \& Goebel, 2013; Goebel et al., 2015; Goebel, unpubl.; Nuerk et al., 2005), all numerals between 0-9 were used. Here we provide these 5 datasets considering all numerals presented. Data filters in these datasets were applied for consistency.

Each file comprises the following variables:

part.code - The same as in "Block_order_demographics" and "Raw_data_sets_as_reported_in_the_paper" (see above for details).

age - participant's age in years (integers only; see above for details).

gender - participant's gender (see above for details).

block.order - order of blocks (see above for details).

block.no- block number according to order of administration (see above for details).

series - Present in 3 datasets; Cipora \& Goebel, 2013; Goebel et al., 2015, Goebel, unpubl (see above for details).

trial.no - trial number. Continuous numbering from 1 until the number of the last trial performed by a given participant. Here a new trial numbering was applied compared to Raw_data_sets_as_reported_in_the_paper so that trial numbers consider 0 and 5 .

number - numeral presented to the participant in a given trial. Possible values: $0,1,2,3,4,5,6,7,8,9$.

resp.side - response, on which the correct response button was located (see above for details).

$r t$ - reaction time in milliseconds.

correct.experimental - filtering variable excluding incorrect responses and trials in which participants did not respond at all (see above for details).

The last two variables are again specific to the analysis approach taken by Cipora, and Dijck et al. (2019), and can be ignored if one decides on another way of data trimming or filtering. 
filter.correct.exp.antic - filtering variable excluding anticipations $<200$ milliseconds (see above for details).

filter.seq - sequential filter (see above for details).

\section{"Block_order_demographics"}

As stated above, the demographic data are included in each dataset, but due to the organization of these datafiles, this information is replicated in multiple rows corresponding to trials performed by a given participant. For this reason, we also provide this data in a simplified format, in which one row corresponds to one participant.

Basic demographic data (age and gender) of participants for all datasets. Additionally, the order of blocks administered to each participant is provided. Each file corresponds to one dataset, and each row within these datasets corresponds to one participant. Using the $\mathrm{R}$ script stored in this folder one can merge the demographic data into one data frame.

Each file comprises the following variables, each of them corresponds to the respective variables in the raw data files:

part.code

block.order

gender

age 
Table 2. Task parameters of considered datasets and basic performance measures

\begin{tabular}{|c|c|c|c|c|c|c|c|c|c|c|c|}
\hline \multirow[t]{2}{*}{ Data set } & \multicolumn{9}{|c|}{ Task parameters } & \multicolumn{2}{|c|}{ Performance } \\
\hline & $\begin{array}{l}\text { Softwar } \\
\text { e }\end{array}$ & $\begin{array}{l}\text { Response } \\
\text { keys }\end{array}$ & $\begin{array}{l}\text { Trial } \\
\text { randomization }\end{array}$ & $\begin{array}{l}\text { Number } \\
\text { range }\end{array}$ & $\begin{array}{l}\text { Block } \\
\text { order a }\end{array}$ & $\begin{array}{c}\text { Repetiti } \\
\text { ons / } \\
\text { conditio } \\
n\end{array}$ & $\begin{array}{c}\text { Fixation } \\
\text { point } \\
\text { [ms] }\end{array}$ & $\begin{array}{l}\text { Respons } \\
\text { e } \\
\text { deadline } \\
\text { [ms] }\end{array}$ & $\begin{array}{c}\text { Intertrial } \\
\text { interval } \\
\text { [ms] }\end{array}$ & $\begin{array}{l}\text { Accu } \\
\text { racy }\end{array}$ & $\begin{array}{c}\text { Reacti } \\
\text { on } \\
\text { time } \\
\text { [ms] }\end{array}$ \\
\hline $\begin{array}{l}\text { Cipora et al. } \\
(2009)\end{array}$ & $\begin{array}{l}\text { SuperL } \\
a b\end{array}$ & $\begin{array}{l}\text { Keyboard: } \\
\text { A and L }\end{array}$ & Fully randomized & $0-9$ & $\mathrm{C}$ & 12 & 300 & 1500 & 500 & .95 & 557.5 \\
\hline $\begin{array}{l}\text { Cipora \& } \\
\text { Göbel (2013) }\end{array}$ & E-prime & $\begin{array}{l}\text { Keyboard: } 1 \\
\text { and } 0 \text { (top } \\
\text { row) }\end{array}$ & \multirow{4}{*}{$\begin{array}{l}\text { Randomized } \\
\text { within each full } \\
\text { set of numbers } \\
\text { and then } \\
\text { repeated }\end{array}$} & $0-9$ & C & 9 & 1500 & 2000 & none & .96 & 635.6 \\
\hline $\begin{array}{l}\text { Cipora \& } \\
\text { Nuerk (2013) }\end{array}$ & \multirow{3}{*}{ DMDX } & \multirow{3}{*}{$\begin{array}{l}\text { Keyboard: } \\
P \text { and } Q\end{array}$} & & $1-4 ; 6-9$ & C & 20 & 300 & 2000 & 500 & .94 & 549.0 \\
\hline $\begin{array}{l}\text { Cipora et al. } \\
(2016)\end{array}$ & & & & $1-4 ; 6-9$ & C & 30 & 300 & 2000 & 500 & .97 & 561.1 \\
\hline Cipora (2014) & & & & $1-4 ; 6-9$ & $\mathrm{C}$ & 30 & 300 & 2000 & 500 & .96 & 596.2 \\
\hline $\begin{array}{l}\text { Georges et al. } \\
(2016)\end{array}$ & \multirow{7}{*}{ E-prime } & \multirow{4}{*}{$\begin{array}{l}\text { Keyboard: } \\
\text { A and L }\end{array}$} & \multirow{4}{*}{$\begin{array}{l}\text { Pseudorandomiz } \\
\text { ed for each block: } \\
\text { 1) no number } \\
\text { appearing twice } \\
\text { in a row; 2) the } \\
\text { correct response } \\
\text { not on the same } \\
\text { side > } 3 \text { times in } \\
\text { a row }\end{array}$} & $1-4 ; 6-9$ & $f$ & 9 & 300 & 1300 & 1300 & .97 & 595.3 \\
\hline $\begin{array}{l}\text { Georges et al. } \\
(2017)\end{array}$ & & & & $1-4 ; 6-9$ & $f$ & $9^{b}$ & 300 & 1300 & 1300 & .97 & 614.0 \\
\hline $\begin{array}{l}\text { Georges et al. } \\
(2018)\end{array}$ & & & & $1-4 ; 6-9$ & $f$ & 18 & 300 & 1300 & 1300 & .97 & 650.4 \\
\hline $\begin{array}{l}\text { Georges et al. } \\
\text { (unpubl.) }\end{array}$ & & & & $1-4 ; 6-9$ & $f$ & 9 & 300 & 1300 & 1300 & .95 & 540.8 \\
\hline $\begin{array}{l}\text { Ginsburg et al. } \\
\text { (unpubl.) }\end{array}$ & & $\begin{array}{l}\text { Keyboard: } \\
\text { S and L }\end{array}$ & Fully randomized & $1-4 ; 6-9$ & C & 20 & 500 & 3000 & 750 & .95 & 520.7 \\
\hline $\begin{array}{l}\text { Göbel } \\
\text { (unpubl.) }\end{array}$ & & \multirow{2}{*}{$\begin{array}{l}\text { Keyboard: } 1 \\
\text { and } 0 \text { (top } \\
\text { row) }\end{array}$} & \multirow{2}{*}{$\begin{array}{l}\text { Randomized } \\
\text { within each full } \\
\text { set of numbers } \\
\text { and then } \\
\text { repeated }\end{array}$} & $0-9$ & C & 9 & 1500 & 2000 & none & .94 & 675.3 \\
\hline $\begin{array}{l}\text { Göbel et al. } \\
(2015)\end{array}$ & & & & $0-9$ & C & 9 & 1500 & 2000 & none & .96 & 607.8 \\
\hline
\end{tabular}




\begin{tabular}{|c|c|c|c|c|c|c|c|c|c|c|c|}
\hline $\begin{array}{l}\text { Masson \& } \\
\text { Pesenti } \\
\text { (unpubl.) }\end{array}$ & & $\begin{array}{l}\text { Keyboard: } \\
\text { Left and } \\
\text { right arrow }\end{array}$ & \multirow{3}{*}{ Fully randomized } & $1-4 ; 6-9$ & C & 16 & 1000 & none & 500 & .97 & 539.2 \\
\hline $\begin{array}{l}\text { Nuerk et al. } \\
(2005)^{c}\end{array}$ & $\begin{array}{l}\text { Present } \\
\text { ation }\end{array}$ & $\begin{array}{l}\text { External } \\
\text { response } \\
\text { keys } 26 \mathrm{~cm} \\
\text { apart }\end{array}$ & & $0-9$ & $C$ & 10 & 500 & 1500 & none & .94 & 502.8 \\
\hline $\begin{array}{l}\text { van Dijck et al. } \\
(2009)\end{array}$ & \multirow{4}{*}{ E-prime } & $\begin{array}{l}\text { External } \\
\text { response } \\
\text { keys } 9.5 \mathrm{~cm} \\
\text { apart }\end{array}$ & & $1-4 ; 6-9$ & C & 16 & 500 & none & 500 & .95 & 534.9 \\
\hline $\begin{array}{l}\text { van Dijck et al. } \\
\text { (unpubl., a) }\end{array}$ & & \multirow{3}{*}{$\begin{array}{l}\text { Keyboard: J } \\
\text { and F }\end{array}$} & \multirow{3}{*}{$\begin{array}{l}\text { Randomized in } \\
\text { blocks of } 64 \text { trials, } \\
\text { with no numbers } \\
\text { appearing twice } \\
\text { in a row in each } \\
\text { block }\end{array}$} & $1-4 ; 6-9^{d}$ & C & 24 & 500 & 1500 & 1000 & .93 & 578.3 \\
\hline $\begin{array}{l}\text { van Dijck et al. } \\
\text { (unpubl., b) }\end{array}$ & & & & $1-4 ; 6-9$ & C & 24 & 500 & 1500 & 1000 & .92 & 598.8 \\
\hline $\begin{array}{l}\text { van Dijck et al. } \\
\text { (unpubl., c) }\end{array}$ & & & & $1-4 ; 6-9$ & C & 32 & 500 & 1500 & 1000 & .94 & 581.8 \\
\hline
\end{tabular}

${ }^{a} \mathrm{C}=$ counterbalanced between participants; $f$ = fixed, starting with a block with right hand / left responses to even / odd numbers respectively

$\mathrm{b}$ three participants were administered with more trials than the rest of the participants

${ }^{c}$ this is the only study, in which blocks were intermixed with other binary decision tasks, e.g., parity judgment of numbers presented

in another modality. In all other studies parity judgment blocks were administered immediately one after another.

d numbers presented upright or in italics for consistency with other blocks 


\section{Basic data quality checks}

All datasets comprise data from participants who completed the task and were retained for further analyses. Participants for whom there was no possibility to estimate the SNARC effect due to low accuracy were excluded. Specifically, estimating the SNARC is not possible with the typical method when there is no valid reaction time in any of number * response side cell. That means, out of several repetitions of the trial within a block (here between 9 and 32; see Table 2), the participant failed to accurately (and within the outlier reaction time trimming criteria as described above) judge the parity of a given numeral even once. Given the simplicity of the parity judgment task and overall accuracy, these are in most cases individuals who either misunderstood the instructions or failed to switch the response rule mid-experiment. Additionally, in the case of published studies, here we consider only participants who were included in the analyses reported in the respective papers.

Mean accuracy in each dataset along with mean reaction time (correct responses only) are presented in Table 2. In all datasets, a robust SNARC effect was observed (see Cipora, van Dijck, et al., 2019). We do not report these analyses here, as our goal here is to present this extensive dataset and ways it can be used in future studies. We also outline benefits of similar initiatives for other tasks widely used in cognitive psychology.

\section{Discussion and perspectives}

The SNARC-B-PJ database comprises raw, trial-level datasets of a very popular task in numerical cognition when it comes to evaluating SNAs. These datasets were collected in different countries, involved speakers of different languages, and in that sense provide a good overview of results one might obtain administering the typical SNARC-B-PJ to adults. Having access to such a database gives the opportunity to test multiple specific predictions about the SNARC effect (or processing of single Arabic numeral in general) without the necessity for new data collection. This can prove useful for instance to estimate effect sizes to be searched for in new experiments or give a realistic overview of outcomes one might suspect in that setup. Given that datafiles are organized in a uniform manner, one can run the same analyses on 18 datasets in parallel. Below we present a tentative overview of potential analyses one could run on this database. 


\section{Potential further analyses}

Meta-analyses. Various kinds of meta-analyses can be informed by such trial-level data. More fine-grained analyses are possible when one has access to the very raw data rather than to study-level effect sizes.

Serial effects. Even though the studies were not specifically designed to investigate serial effects on the SNARC effect, having trials randomized and having the actual order of trials available makes it possible to at least tentatively test for serial Grattonlike effects. This can be useful for designing future experiments specifically aimed at these issues.

Linear mixed models. Given the number of different samples, overall sample size, and availability of trial-level data, it is sufficient for various analysis using linear mixed models.

Different analysis pipelines. Trial-level data allows testing for optimal ways of data filtering, preprocessing, and analysis. One can also test for effects of such preprocessing on experimental effects of interest (Silberzahn et al., 2018; Steegen et al., 2016). Given a relatively large number of studies, such analyses can be cross validated across data from different experiments. As data on errors are also available, one can explore possibilities for combining these measures, and for optimizing the bootstrap techniques proposed to investigate individual differences in the SNARC (Cipora, van Dijck, et al., 2019).

Other numerical effects. Having trial-level data, one might also investigate other numerical effects using this large-scale data set. To name only a few, one may study parity to response side associations (the MARC effect; Nuerk et al., 2004), the effect of parity on reaction time (the odd effect; Hines, 1990), or relations between numerical magnitude and reaction time (the size effect, e.g., Hohol et al., 2020).

\section{Perspectives for the development of the database}

We do not wish to confine this database to its current form. We would rather like to encourage interested authors to contribute their datasets to this resource ${ }^{1}$. What would be particularly valuable would be increasing the diversity of the samples available. So far, most of the data comes from relatively young, white European students. Even though our participants came from five different European countries,

\footnotetext{
${ }^{1}$ Researchers willing to contribute their data should contact the corresponding author.
} 
all of them could be classified as WEIRD (Western, Educated, Industrialized, Rich, and Democratic; Henrich et al., 2010). Extending the database would allow scaling up analyses regarding the ideas we listed above and conducting even more advanced and fine-grained analyses. Specifically, as for now, several parameters of the task were consistently used by specific labs, so one cannot disentangle which of the parameters can have a specific effect on the observed reaction time pattern / SNARC. Ideally, having more datasets from other labs using other configurations of parameters can help disentangling the role played by different task parameter configurations.

\section{Getting a broader perspective}

SNARC-B-PJ is only one of many popular tasks in cognitive psychology. We believe that a similar approach can be useful and feasible for other popular cognitive psychology tasks. Having a database of well-documented trial-level datasets can facilitate data syntheses and additional insights like those mentioned above or even extending them. We guess that multiple datasets exist in several labs that can potentially be unified and shared with the community, providing mutual benefit for both those, who share them - via additional citations and prospects of new collaborations and those who analyze them and provide new insights into the effect of interest by secondary analysis.

Our reading of the literature suggests that even in case of "standard" cognitive tasks, there are quite some variations between procedures used as regards response setup, trial timings, number of trials, etc. Presence of these variations in the tasks being used and lack of understanding of their true influences makes it tempting for researchers to point to them as the mythical "hidden moderators" responsible for conflicting results. Data syntheses can shed some light on which of these parameters do and do not play a role, and what their influence is.

\section{Potential benefits for training students}

Databases as described above cannot only provide material for strictly scientific endeavors, but also a handy resource for student projects. Very recently, Button and colleagues (2020) pointed out, that student projects often suffer from low budget and time constraints, both of which prevent collecting sufficiently large samples. Thus, analyses are underpowered, and more likely to present both false negatives and false positives. As an unintended consequence, students learn "bad" science as a part of 
their training. Apart from solutions proposed by Button et al. (2020), we think that involving student projects in such initiatives can prove useful in several stages: (1) contributing to such resources by curating datasets existing in the lab can serve as training for data management and transparency in science; (2) using such datasets can be useful for training data analysis skills and can actually bring relatively trustable results; (3) projects focused on collecting new data can potentially fill in "the gaps" in existing data (e.g., using a profile of task parameters, which can be useful to disentangle, which parameter is crucial to understand potential discrepancies between existing datasets), and use the whole database for the analysis.

\section{Summary}

This work shows the benefits of creating and developing large databases in two ways. First, we believe that presenting these datasets on SNARC-B-PJ will be useful for numerical cognition researchers advancing data syntheses and more complex analyses for our understanding of Spatial-Numerical Associations. Second, even more important, we believe that this work serves as an example for similar initiatives for popular effects in cognitive psychology. We hope it will inspire other researchers to create similar datasets for other popular tasks in their respective domains.

\section{Acknowledgements}

$\mathrm{KC}$ is funded by Research England via the Centre for Mathematical Cognition. MP is a Senior Research Associate at the Fonds National de la Recherche Scientifique (FRS-FNRS, Belgium). NM is supported by grant PDR-T.0047.18 and INTER/FNRS/17/11781524/SNAMATH from the Fonds National de la Recherche Scientifique (FRS-FNRS, Belgium) and the Fonds National de la Recherche (FNR, Luxembourg) to MP and CS. The collection of data contributed by SG was supported by a British Academy/Leverhulme Small Research Grant [SG121544]. HCN is a member of LEAD Graduate School \& Research Network [GSC1028], which is funded within the framework of the Excellence Initiative of the German federal and state governments as well as by two German Research Foundation (DFG) projects examining the understanding and replicability of Spatial-Numerical Associations (DFG NU265/8-1 and DFG-FOR 2718 Teilprojekt NU 265/5-1) 
Conflict of Interest

The authors declare that they have no conflicts of interest. 


\section{References}

Brigadoi, S., Basso Moro, S., Falchi, R., Cutini, S., \& Dell'Acqua, R. (2018). On pacing trials while scanning brain hemodynamics: The case of the SNARC effect. Psychonomic Bulletin \& Review, 25, 2267-2273. https://doi.org/10.3758/s13423-017-1418-1

Button, K. S., Chambers, C. D., Lawrence, N., \& Munafò, M. R. (2020). Grassroots Training for Reproducible Science: A Consortium-Based Approach to the Empirical Dissertation. Psychology Learning and Teaching, 19(1), 77-90. https://doi.org/10.1177/1475725719857659

Cipora, K. (2014). Between task consistency of the SNARC effect. Poster Presented at XXXIInd European Workshop at Cognitive Neuropsychology.

Cipora, K., Czernecka, K., \& Szymura, B. (2009). Temperamental differences in the magnitude of the SNARC effect. Poster Presented at International Society for the Study of Individual Differences.

Cipora, K., \& Göbel, S. M. (2013). Number - Space associations: Just how reliable is the SNARC effect. Poster Presented on XXXIst European Workshop at Cognitive Neuropsychology.

Cipora, K., Haman, M., Domahs, F., \& Nuerk, H.-C. (2020). Editorial: On the Development of Space-Number Relations: Linguistic and Cognitive Determinants, Influences, and Associations. Frontiers in Psychology, 11(February), 1-5. https://doi.org/10.3389/fpsyg.2020.00182

Cipora, K., Hohol, M., Nuerk, H.-C., Willmes, K., Brożek, B., Kucharzyk, B., \& Nęcka, E. (2016). Professional mathematicians differ from controls in their spatial-numerical associations. Psychological Research, 80(4), 710-726. https://doi.org/10.1007/s00426015-0677-6

Cipora, K., \& Nuerk, H.-C. (2013). Is the SNARC effect related to the level of mathematics? No systematic relationship observed despite more power, more repetitions, and more direct assessment of arithmetic skill. Quarterly Journal of Experimental Psychology, 66(10), 1974-1991. https://doi.org/10.1080/17470218.2013.772215

Cipora, K., Schroeder, P. A., Soltanlou, M., \& Nuerk, H.-C. (2018). More space, better mathematics: Is space a powerful tool or a cornerstone for understanding arithmetic? In K. S. Mix \& M. T. Battista (Eds.), Visualizing Mathematics: The Role of Spatial Reasoning in Mathematical Thought (pp. 77-116). Springer Cham. https://doi.org/10.1007/978-3-319-98767-5_4 77

Cipora, K., Soltanlou, M., Reips, U.-D., \& Nuerk, H.-C. (2019). The SNARC and MARC effects measured online: Large-scale assessment methods in flexible cognitive effects. Behavior Research Methods, 51(4), 1676-1692. https://doi.org/10.3758/s13428-01901213-5

Cipora, K., Soltanlou, M., Smaczny, S., Göbel, S. M., \& Nuerk, H.-C. (2021). Automatic placevalue activation in magnitude-irrelevant parity judgement. Psychological Research, 85(777), 792. https://doi.org/10.1007/s00426-019-01268-1

Cipora, K., van Dijck, J.-P., Georges, C., Masson, N., Göbel, S. M., Willmes, K., Pesenti, M., Schiltz, C., \& Nuerk, H.-C. (2019). A Minority pulls the sample mean: on the individual prevalence of robust group-level cognitive phenomena - the instance of the SNARC effect. PsyArXiv. https://doi.org/10.31234/osf.io/bwyr3

Cipora, K., \& Wood, G. (2017). Finding the SNARC instead of hunting it: A 20*20 monte carlo investigation. Frontiers in Psychology, 8(JUL).

https://doi.org/10.3389/fpsyg.2017.01194 
Curran, P. J., \& Hussong, A. M. (2009). Integrative Data Analysis: The Simultaneous Analysis of Multiple Data Sets. Psychological Methods, 14(2), 81-100.

https://doi.org/10.1037/a0015914

Dehaene, S., Bossini, S., \& Giraux, P. (1993). The mental representation of parity and number magnitude. Journal of Experimental Psychology: General, 122(3), 371-396.

Forster, K., \& Forster, J. (2003). DMDX: A Windows display program with millisecond accuracy. Behavior Research Methods, Instruments, \& Computers, 35(1), 116-124. https://doi.org/10.3758/BF03195503

Georges, C., Hoffmann, D., \& Schiltz, C. (2016). How math anxiety relates to number-space associations. Frontiers in Psychology, 7(SEP), 1-15.

https://doi.org/10.3389/fpsyg.2016.01401

Georges, C., Hoffmann, D., \& Schiltz, C. (2017). How and Why Do Number-Space Associations Co-Vary in Implicit and Explicit Magnitude Processing Tasks? Journal of Numerical Cognition, 3(2), 182-211.

Georges, C., Hoffmann, D., \& Schiltz, C. (2018). Implicit and Explicit Number-Space Associations Differentially Relate to Interference Control in Young Adults With ADHD. Frontiers in Psychology, 9, 775. https://doi.org/10.3389/fpsyg.2018.00775

Gevers, W., Verguts, T., Reynvoet, B., Caessens, B., \& Fias, W. (2006). Numbers and space: A computational model of the SNARC effect. Journal of Experimental Psychology: Human Perception and Performance, 32(1), 32-44. https://doi.org/10.1037/0096-1523.32.1.32

Göbel, S. M., Maier, C. A., \& Shaki, S. (2015). Which numbers do you have in mind? Number generation is influenced by reading direction. Cognitive Processing, 16(S1), 241-244. https://doi.org/10.1007/s10339-015-0715-8

Gökaydin, D., Brugger, P., \& Loetscher, T. (2018). Sequential Effects in SNARC. Scientific Reports, 8(1), 1-13. https://doi.org/10.1038/s41598-018-29337-2

Henrich, J., Heine, S. J., \& Norenzayan, A. (2010). The weirdest people in the world? Behavioral and Brain Sciences, 33(2-3), 61-83. https://doi.org/10.1017/S0140525X0999152X

Heubner, L., Cipora, K., Soltanlou, M., Schlenker, M.-L., Lipowska, K., Göbel, S. M., Domahs, F., Haman, M., \& Nuerk, H.-C. (2018). A mental odd-even continuum account: Some numbers may be "more odd" than others and some numbers may be "more even" than others. Frontiers in Psychology, 9(JUN). https://doi.org/10.3389/fpsyg.2018.01081

Hines, T. M. (1990). An odd effect: Lengthened reaction times for judgments about odd digits. Memory \& Cognition, 18(1), 40-46. https://doi.org/10.3758/BF03202644

Hohol, M., Willmes, K., Nęcka, E., Brożek, B., Nuerk, H.-C., \& Cipora, K. (2020). Professional mathematicians do not differ from others in the symbolic numerical distance and size effects. Scientific Reports, 10(1), 1-12. https://doi.org/10.1038/s41598-020-68202-z

Hussong, A. M., Curran, P. J., \& Bauer, D. J. (2013). Integrative data analysis in clinical psychology research. Annual Review of Clinical Psychology, 9, 61-89. https://doi.org/10.1146/annurev-clinpsy-050212-185522

Nuerk, H.-C., Iversen, W., \& Willmes, K. (2004). Notational modulation of the SNARC and the MARC (linguistic markedness of response codes) effect. Quarterly Journal of Experimental Psychology Section A: Human Experimental Psychology, 57(5), 835-863. https://doi.org/10.1080/02724980343000512

Nuerk, H.-C., Wood, G., \& Willmes, K. (2005). The universal SNARC effect: The association between number magnitude and space is amodal. Experimental Psychology, 52(3), 187-194. https://doi.org/10.1027/1618-3169.52.3.187 
Open Science Collaboration. (2015). PSYCHOLOGY. Estimating the reproducibility of psychological science. Science, 349(6251), aac4716.

https://doi.org/10.1126/science.aac4716

Pfister, R., Schroeder, P. A., \& Kunde, W. (2013). SNARC struggles: Instant control over spatial-numerical associations. Journal of Experimental Psychology: Learning Memory and Cognition, 39(6), 1953-1958. https://doi.org/10.1037/a0032991

Schiller, F., Eloka, O., \& Franz, V. H. (2016). Using Key Distance to Clarify a Theory on the SNARC. Perception, 45(1-2), 196-221. https://doi.org/10.1177/0301006615616754

Silberzahn, R., Uhlmann, E. L., Martin, D. P., Anselmi, P., Aust, F., Awtrey, E., Bahník, Š., Bai, F., Bannard, C., Bonnier, E., Carlsson, R., Cheung, F., Christensen, G., Clay, R., Craig, M. A., Dalla Rosa, A., Dam, L., Evans, M. H., Flores Cervantes, I., ... Nosek, B. A. (2018). Many Analysts, One Data Set: Making Transparent How Variations in Analytic Choices Affect Results. Advances in Methods and Practices in Psychological Science, 1(3), 337356. https://doi.org/10.1177/2515245917747646

Steegen, S., Tuerlinckx, F., Gelman, A., \& Vanpaemel, W. (2016). Increasing Transparency Through a Multiverse Analysis. Perspectives on Psychological Science, 11(5), 702-712. https://doi.org/10.1177/1745691616658637

Toomarian, E. Y., \& Hubbard, E. M. (2018). On the genesis of spatial-numerical associations: Evolutionary and cultural factors co-construct the mental number line. Neuroscience \& Biobehavioral Reviews, 90, 184-199. https://doi.org/10.1016/J.NEUBIOREV.2018.04.010

Vallesi, A., Shallice, T., \& Walsh, V. (2006). Role of the Prefrontal Cortex in the Foreperiod Effect: TMS Evidence for Dual Mechanisms in Temporal Preparation. Cerebral Cortex, 17(2), 466-474. https://doi.org/10.1093/cercor/bhj163

van Dijck, J.-P., Gevers, W., \& Fias, W. (2009). Numbers are associated with different types of spatial information depending on the task. Cognition, 113(2), 248-253. https://doi.org/10.1016/j.cognition.2009.08.005

Wood, G., Willmes, K., Nuerk, H.-C., \& Fischer, M. H. (2008). On the cognitive link between space and number: a meta-analysis of the SNARC effect. Psychology Science Quarterly, 4(4), 489-525. https://doi.org/10.1027/1618-3169.52.3.187 